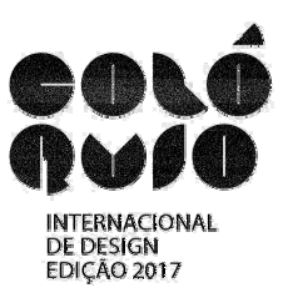

\title{
Material Didático Digital para o Ensino de Iluminação Artificial na Fotografia
}

\author{
Elisangela Lobo Schirigatti
}

resumo:

Este trabalho tem como objetivo descrever o processo de desenvolvimento de um material didático digital para o Laboratório de Narrativas Visuais do Departamento Acadêmico de Desenho Industrial da Universidade Tecnológica Federal do Paraná (UTFPR). O projeto de design teve a finalidade de melhorar e unificar o ensino e o aprendizado na área fotográfica, abordando o tema de iluminação artificial. A metodologia ADDIE foi utilizada a fim de guiar as análises e os pontos a serem observados e registrados no presente material. O projeto foi dividido em cinco etapas: análise, geração de alternativas, desenvolvimento, implementação e avaliação. Primeiro, foi realizada a identificação de todos os equipamentos de iluminação disponíveis no laboratório por meio da captação de imagens. Em seguida, cada material foi conceituado com suas respectivas especificações técnicas e descrito para quais fins podem ser utilizados. Além disso, nessa fase de análise fez-se necessário um estudo aprofundado sobre as técnicas de iluminação na fotografia e as funções da câmera que influenciam na iluminação. Essa fundamentação teórica foi importante para que o material fosse composto por conteúdos apropriados. Ademais, foram realizadas observações e registros durante as aulas de fotografia para que fosse possível compreender as dificuldades e as carências por parte dos alunos e, assim, desenvolver um material mais eficiente e atrativo. A partir das observações feitas na fase de análise, foi possível chegar ao conceito do projeto: criar um material didático digital no estilo do design escandinavo seguindo regras de diagramação para compor os layouts. O design escandinavo tem como características o minimalismo, formas retas, cores neutras, simplicidade e elegância. Com isso definido, iniciou-se a fase criativa, com a geração de alternativas, que ocorreu por meio de desenhos feitos à mão. Em seguida, foram escolhidas as alternativas mais viáveis, ou seja, aquelas que poderiam proporcionar maior receptividade por parte do usuário. Com essas informações, foi possível passar para a parte prática, a execução do projeto propriamente dito. Para a realização do projeto, foram utilizados softwares como o CorelDraw, Illustrator e Photoshop. Após a finalização, ocorreu a implementação e, em seguida, a avaliação do material pelos alunos e professores. Por fim, as alterações sugeridas foram realizadas, como a mudança da regra de diagramação (os grids modulares e em coluna foram substituídos pela regra da proporção áurea), o tamanho da fonte que compunha o texto (de 19 pontos para 12), a inclusão de mais informações, o modo de apresentação do material (versão final com capa dura), entre outras modificações. O conteúdo do material didático criado compreendeu diversos assuntos: breve explicação das técnicas de iluminação fotográfica, tais como: luz frontal, lateral, dura, suave, high key, low key e contraluz, descrição de cada equipamento fotográfico e dos acessórios de iluminação disponíveis no laboratório, e de como estes podem ser utilizados para compor as técnicas de iluminação. A princípio, o material foi elaborado para o meio digital, pela facilidade de acesso, porém, uma versão foi impressa e está disponível no laboratório para consultas rápidas. Em suma, o resultado deste projeto foi um material didático bastante prático, direto, de fácil compreensão e com a simplicidade e elegância do design escandinavo.

\section{palavras-chave:}

Design escandinavo; Metodologia ADDIE; Fotografia de estúdio; Equipamento fotográfico 


\section{Introdução}

A função da luz na fotografia é alterar a textura, o volume, o contraste e a coloração. Existe a luz natural (o sol) e a luz artificial (luz contínua e flash). Tanto a luz natural, quanto a luz artificial são complexas e permitem manipulação, contudo a artificial é mais passível de se controlar e alterar, pois pode-se reduzir a intensidade; aumentar ou diminuir a quantidade de equipamentos de iluminação (cabeças de flash ou luz contínua), utilizar difusores, rebatedores ou concentradores, e com a dominação desses fatores a iluminação artificial tem grande impacto na fotografia e é essa habilidade de usar a luz que diferencia "pequenos" fotógrafos de grandes nomes na fotografia (REGINA; TAKAZAKI, 2015).

Desta forma, é fundamental compreender os efeitos de sentido que a luz produz em cada fotografia, a pessoa que está fotografando deve saber qual é sua intenção naquela fotografia, para decidir qual tipo de iluminação irá utilizar. Por exemplo, se o objetivo for dramatizar, a luz dura será o ideal, pois ela produz sombras bem marcadas. Segundo Lüersen (2007), outros fatores também devem ser levados em consideração no momento de compor uma fotografia, como a direção da fonte de luz, o tamanho, a intensidade e a qualidade, pois esses elementos interferem diretamente no contraste, iluminação, nos detalhes e, especialmente, na informação que ela passa. Além destes, outra informação a ser considerada é a temperatura de cor que traz dominantes (ROWSE, 2017).

Por isso, a iluminação artificial é um tema muito abordado por diversos autores (CURTIN, 2007; REGINA, 2015; LIMA, 2016; DALBELLO, 2016), seu conteúdo técnico engloba outras disciplinas, inclusive a física (RAMALHO, 2004), e sua prática é muito usual nas disciplinas de fotografia. Apesar de existir muitos materiais que abordam o assunto, a maioria não é voltado para a prática em sala de aula. Além disso, os materiais digitais online se encontram espalhados em diferentes sites, sendo comum a presença de inconsistências e a falta de profundidade dos assuntos abordados. Uma das soluções para suprir essa demanda são materiais didáticos que facilitam a prática docente de ensino. Pois, como diz Salgado (2005, p. 155), "o uso de materiais didáticos diversificados permite dinamizar a aula e constituir uma relação entre o aluno e o conteúdo a ser trabalhado".

Com essas informações, conclui-se que a iluminação artificial possui diferentes aplicabilidades na área da fotografia, além de ser útil na área de comunicação, documentação e portfólio. Visto a importância do ensino e o aprendizado da iluminação artificial na fotografia, a proposição de um material de apoio voltado a esse tema no curso de Design se caracteriza como um forte instrumento que pode facilitar a assimilação do conteúdo e a aplicação prática por parte do aluno.

Por fim, o objetivo geral deste trabalho é descrever o processo de desenvolvimento de um material didático digital para o Laboratório de Narrativas Visuais do Departamento Acadêmico de Desenho Industrial da UTFPR. O projeto de design teve finalidade de melhorar e unificar o ensino e o aprendizado na área fotográfica, abordando o tema de iluminação artificial.

\section{Fundamentação Teórica}

\subsection{Luz frontal e luz lateral}

A fonte de luz pode ser posicionada de diversas formas em relação ao objeto a ser fotografado. Dependendo da direção de onde vem a luz em uma fotografia, cria-se diferentes sensações (REGINA, 2015). A luz frontal é aquela em que a luz está posicionada em frente ao objeto. Iluminar um assunto dessa forma cria uma fotografia com poucas sombras e, por isso, com pouco volume. Um exemplo disso é o flash embutido em cima da câmera, ele ilumina tudo e dessa maneira não cria volumes em uma imagem.

Seguindo o pensamento de Regina (2015), a luz lateral é aquela em que a luz é posicionada ao lado do assunto fotografado (Figura 1), normalmente a $45^{\circ}$. Essa posição - a $45^{\circ}$ - é chamada de 
Rembrandt e é muito utilizada para retratos. A luz lateral é mais utilizada do que a luz frontal, pois aquela dá volume aos objetos, deixando a foto mais interessante.
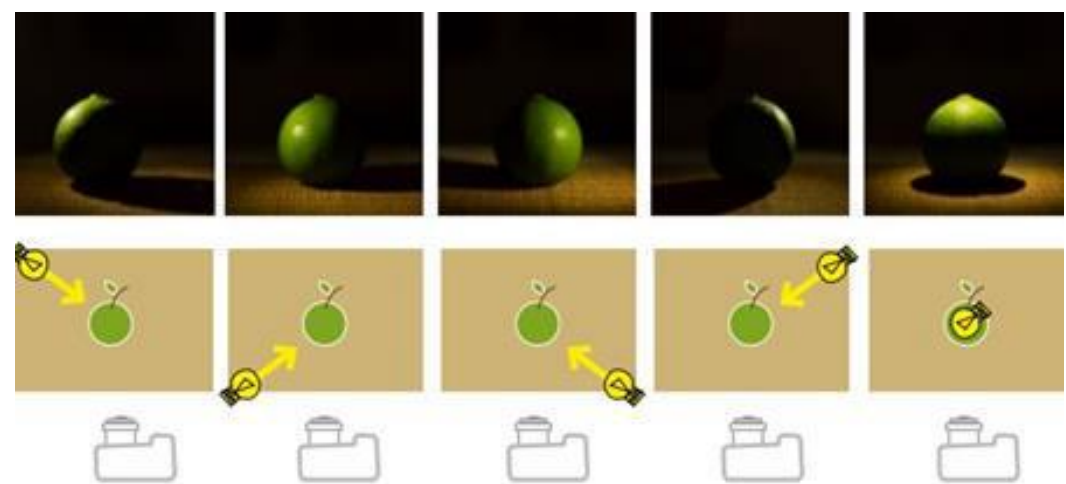

Figura 1 - Diferentes posições da luz e seus respectivos resultados na fotografia. Fonte: Regina (2015).

\subsection{Luz dura e luz suave}

Quando se fala em luz dura e luz suave, na realidade estamos nos referindo da relação entre a luz e sombra. Segundo Regina (2016), luz dura é aquela que se consegue perceber bem o contorno da sombra, quando é fácil de traçar o limite entre a sombra e a luz, como mostra a Figura 2.
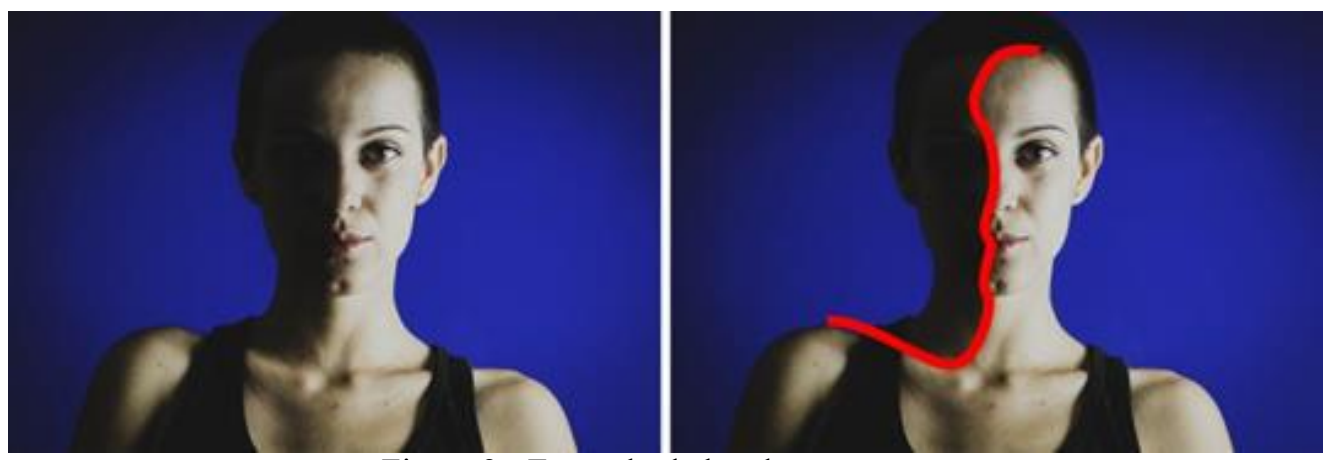

Figura 2 - Exemplo de luz dura.

Fonte: Regina (2016).

Com essa técnica produz-se fotos mais dramáticas e impactantes, pois as cores ficam mais saturadas e pelo fato de existir zonas que ficam estouradas (uma foto "estourada" é aquela que apresenta uma exposição errada da luz: a foto fica clara demais, pois muita luz entrou na câmera). Já a luz suave - chamada também de luz difusa - é quando não é possível distinguir luz e sombra tão facilmente (Figura 3). Mas vale ressaltar que a diferença existe ou não seria possível perceber o objeto como tridimensional. A luz suave provoca sentimentos de paz e calma.

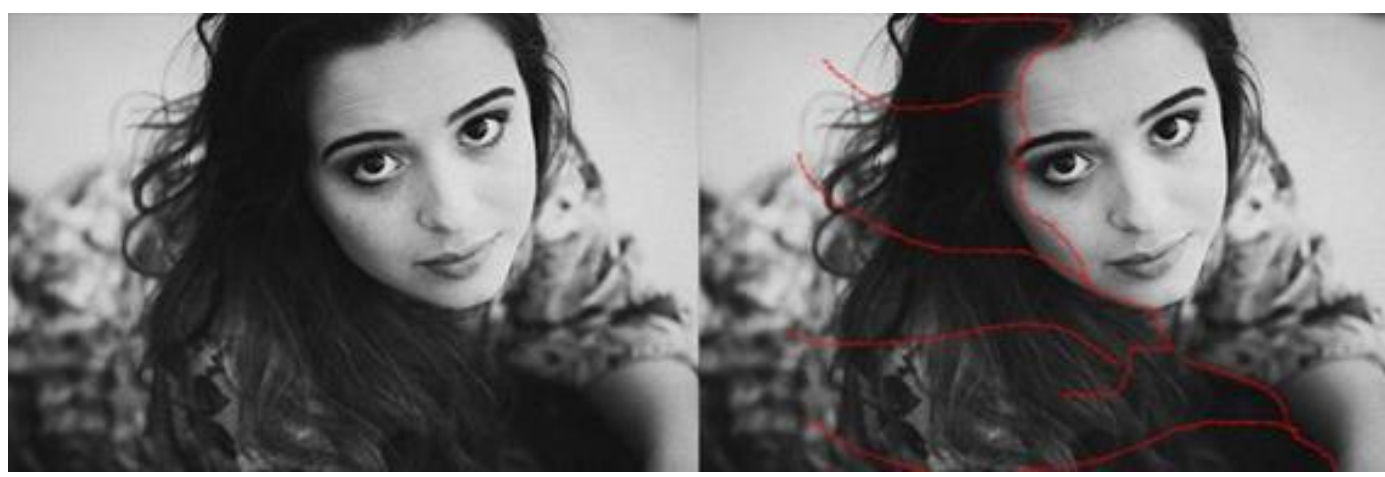

Figura 3 - Exemplo de luz suave.

Fonte: Regina (2016). 
Há diversas maneiras de se obter uma luz dura e suave. De uma maneira bem simples de entender, de acordo com Regina (2016), para se obter uma luz dura é necessária uma fonte de luz pequena, que seja pontual (focada no objeto) e que esteja paralela ao fotografado e para a luz suave é preciso uma fonte de luz maior, produzida por modificadores de luz (difusores). Ou seja, quanto maior for a fonte de luz, mais difusa será sua sombra. Quanto menor ela for, mais dura ficará a sombra. Outro fator que provoca luz dura é quando a fonte luminosa está próxima do objeto a ser fotografado, pois quanto mais afastada está a fonte de luz, mais suave ela será.

Conforme Regina (2016), outro aspecto é que em comparação ao tamanho do assunto a mesma luz pode parecer maior ou menor, ou seja, uma lanterna é uma fonte de luz pequena comparado a uma pessoa, mas é uma fonte grande comparado a um inseto. É por esse motivo que, na maioria das vezes, o sol é uma fonte de luz dura, pois ele é muito "pequeno" em comparação ao objeto, ele só poderá produzir luz suave se for colocado um difusor entre ele e o assunto. Aqui se encontra mais um ensinamento, é possível ter uma luz pequena, pontual, próxima ao objeto e fazer dela uma luz suave, basta colocar um difusor na frente da luz. É por isso que existem difusores, rebatedores e sombrinhas, para transformar luzes, que são sempre do mesmo tamanho, em fontes variadas de efeitos. Por exemplo, nos estúdios é comum observar os fotógrafos usando sombrinhas em frente ao flash para poder espalhar a luz dura e pontual do flash.

\subsection{High key e low key}

Segundo Regina (2016), high key é quando a foto é formada predominantemente por tons mais claros e as sombras são quase inexistentes. Porém, deve-se tomar cuidado, pois não é um efeito fruto de erro de exposição, em que uma foto fica clara demais sem essa intenção (estourada), ela é apenas formada por mais pixels claros do que escuros.

Além do mais, essa técnica é feita normalmente na hora de fazer a foto, e não na edição, pois depende de iluminação, que deve ser bem distribuída, e produção. Esse efeito traz uma sensação alegre e viva para a cena. Em fotos com essa característica, o histograma tem mais informações no lado direito, pois a maior parte da imagem contém tons claros, mas como dito anteriormente, isso não significa que a imagem está errada (Figura 4).

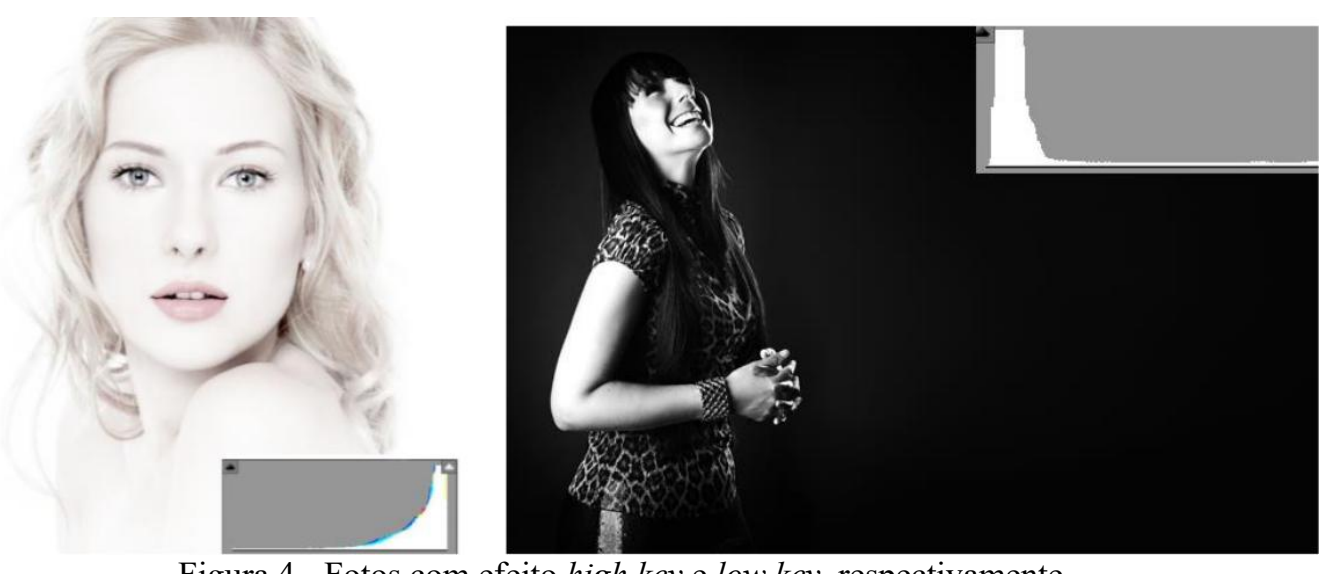

Figura 4 - Fotos com efeito high key e low key, respectivamente.

Fonte: DalBello, 2016.

Já as fotografias low key, o processo é inverso do high key. Elas possuem mais áreas de sombras do que de luzes, como mostra a Figura 4. Da mesma maneira, fotos subexpostas (escuras) não devem ser consideradas fotografias low key. De acordo com Lima (2016), esta técnica é uma boa alternativa quando o ambiente não é favorável para a composição.

Segundo o fotógrafo Lima (2016), para compor uma foto no estilo low key é necessário um conhecimento mais profundo de iluminação, luz e sombras, pois é necessário, em muitos casos, enxergar o resultado da luz antes mesmo de clicar. Por isso estudar luz é essencial. Conforme Dal Bello (2016), neste caso, o histograma pende para o lado esquerdo, ou seja, existe a predominância de tons escuros, sombras e alto contraste. 


\subsection{Contraluz}

A posição do fotógrafo em relação à fonte principal de luz representa outro recurso muito importante na composição fotográfica. Com a fonte principal de luz às suas costas, o fotógrafo terá uma cena francamente iluminada, de leitura visual mais fácil e direta. Já a contraluz - quando o objeto fotografado está entre o fotógrafo e a fonte principal de luz - favorece a sutileza e o mistério (GURAN, 1992, p.34).

Segundo Vieira e Correa (2013), contraluz é quando a fonte de luz está atrás do objeto fotografado, ou seja, "contra você". Nesta situação é possível tomar duas atitudes: fazer uma imagem com silhueta ou compensar a parte que está escura na foto com uma luz auxilia.

Para se obter uma silhueta (Figura 5), é necessário que o assunto esteja de costas para a fonte de luz, o fotógrafo deve fazer a fotometria no fundo e clicar, porém, a luz vinda de trás do fotógrafo precisa ser nula ou quase nula, caso contrário, iluminará o assunto a ser fotografado.
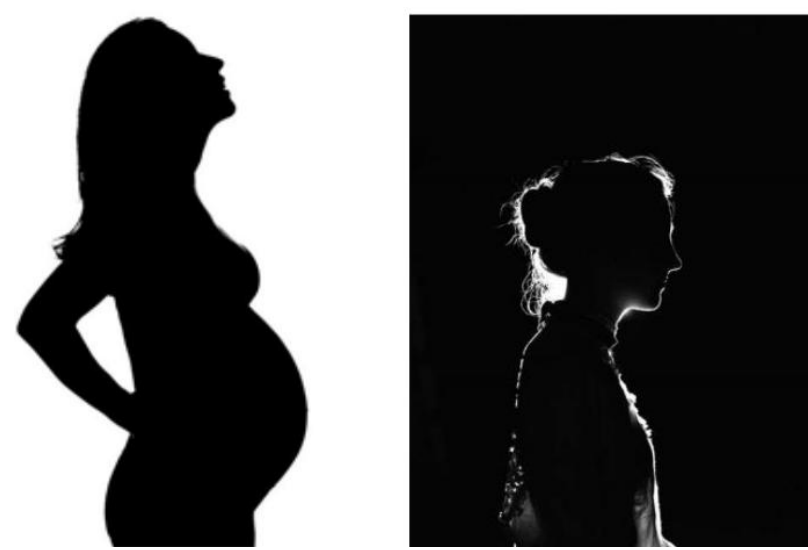

Figura 5 - Fotografia contraluz e silhueta em estúdio.

Fonte: Lourenço (2016) e Worth (2016), respectivamente.

Ainda na Figura 5, é possível observar outro tipo de silhueta produzida em estúdio. Pode-se apagar todas as luzes do ambiente ou colocar um fundo preto e colocar uma fonte de luz atrás do assunto e fotometrar a luz. O fundo ficará escuro e o primeiro plano também, porém terá uma pequena silhueta aparecendo no meio dessa escuridão, dando forma ao objeto. Porém, quando a intenção do autor da imagem não é fazer uma silhueta, mas a fonte de luz ainda sim está atrás do objeto, é possível que ele compense essa falta de luz no primeiro plano acrescentando uma fonte de luz a frente do objeto, neste caso, a fotometria pode ser feita no objeto a ser fotografado. Dessa maneira, o fundo ficará claro e o primeiro plano também.

\section{Metodologia}

A metodologia ADDIE foi adotada para guiar a pesquisa em questão por ser uma das mais abrangentes dentro do contexto proposto e consagrada na literatura científica (FILATRO, 2004). Normalmente, essa metodologia é utilizada para o Design Instrucional (DI) e a estrutura do processo está dividida em cinco etapas principais: A- Analyze (Analisar), D- Design (Projetar), D- Develop (Desenvolver), IImplement (Implementar) e E- Evaluate (Avaliar)

$\mathrm{Na}$ etapa Analyze (Analisar), foi realizada a observação direta das atividades desenvolvidas durante as aulas de fotografia dos cursos de Design da UTFPR. Desta maneira, foi possível identificar as técnicas aplicadas e os equipamentos utilizados ao ensino de iluminação artificial. Além disso, foi feito um registro visual dos equipamentos de iluminação que se encontram no laboratório de Narrativas Visuais da UTFPR, através da captação de imagens fotográficas para que os mesmos pudessem ser catalogados. Em seguida foi realizado um estudo para melhor compreender como cada equipamento pode ser utilizado na composição das técnicas de iluminação. 
Para compor o embasamento teórico sobre iluminação artificial foi realizado uma pesquisa bibliográfica. Assim, foram consultados diversos livros, blog técnicos, slides de aula e artigos científicos sobre o tema.

Uma pesquisa de opinião também foi aplicada para identificar a preferência dos alunos de Design com relação ao material didático a ser desenvolvido (modo digital ou impresso) e quais eram as maiores dificuldades e curiosidades com relação às técnicas que necessitam de luz artificial na fotografia. O questionário foi estruturado na versão impressa e também disponibilizado online (www. typeform.com). Os impressos foram aplicados nos dias 21 e 25 de novembro de 2016 durante a aula de fotografia para as turmas de Tecnologia em Design Gráfico e Bacharelado em Design de todos os períodos. A versão online ficou disponível do dia 14 a 30 de novembro do mesmo ano. O questionário foi elaborado com 15 perguntas, sendo que duas eram descritivas e o restante era de múltipla escolha. Vale lembrar que os dados foram tabulados.

A alternativa mais funcional e eficaz para o ensino e a aprendizagem foi identificada por meio de um estudo sobre os tipos e alternativas de material didático e através das respostas dos alunos no questionário. Este estudo contribuiu para identificar pontos positivos no desenvolvimento do material e quais os fatores de maior relevância que deveriam ser abordados durante o processo. Antes de começar a fase da geração de alternativas foi definido o estilo do projeto e elaborado um moodboard com referências de layout gráfico, objetos e ambientes que serviu de inspiração para a criação do material didático. Nesse caso, as imagens utilizadas foram selecionadas da internet.

Depois da análise fundamentada, passou-se para a segunda etapa - Design (Projetar), a parte criativa de fato, onde foi realizada a geração de alternativas. É um momento em que as ideias devem transcorrer de forma livre e desprendidas de julgamentos, de modo a não bloquearem a criatividade (LÖBACH, 2001). Depois da escolha da alternativa mais viável para desenvolver o projeto final, veio o momento de materializar o que estava apenas no papel, a etapa Develop (Desenvolver), para isso, foi utilizado softwares de criação: CorelDraw, Illustrator e Photoshop.

$\mathrm{Na}$ fase da Implement (Implementar), o material didático foi utilizado pelos alunos de fotografia durante uma aula. Depois de testado para comprovar sua eficiência, na etapa da Evaluate (Avaliar) o conteúdo foi validado. Para identificar se a experiência foi válida ou não, foram realizados testes com os usuários que representavam o público-alvo e foi obtido um feedback por parte de profissionais da área de fotografia e design gráfico. Assim, ao final dos testes, pôde-se identificar os pontos passíveis de correção e arrumá-los.

Os alunos responderam um questionário que continha oito perguntas para fins de avaliação do material desenvolvido. Neste instrumento, as perguntas eram relacionadas à clareza do material e ao design dos layouts. Não foram as mesmas pessoas que responderam o primeiro questionário - àquele feito antes de desenvolver o material-, pois as pessoas que responderam o primeiro já não estão mais cursando a disciplina de Fotografia.

\section{Resultados obtidos}

\subsection{Etapa 1 - Analyze (Analisar)}

Os equipamentos de iluminação artificial que eram utilizados durante as aulas foram identificados e registrados. No total foram constatados doze equipamentos de iluminação artificial na sala C-201 Laboratório de Narrativas Visuais da UTFPR. Nesse montante não foram computados os equipamentos repetidos, mas inclui os acessórios que auxiliam na iluminação, como por exemplo, sombrinhas difusoras. Os equipamentos encontrados nesse ambiente foram: flashes, refletor para flash, snoot, colmeia, softboxes, sombrinhas difusoras, rebatedor, fresnel, refletor parabólico, quartz light, mesa still e fotômetro.

A partir do resultado da pesquisa de campo com os alunos, foi definido que o material didático seria um e-book, o conteúdo do material englobaria a descrição dos equipamentos e acessórios de iluminação artificial, e como cada um pode ser utilizado para compor as técnicas de luz dura, luz suave, luz frontal, luz lateral, high key, low key e contraluz.

O estilo adotado pelo projeto foi o minimalismo do design escandinavo. Segundo a Porto Design (2014), ao se procurar referências sobre ícones do design, a associação com o design escandinavo é natural e imediata, pois desenho simples, funcionalidade, minimalismo, baixo custo, 
redução de elementos, praticidade, beleza, elegância, sofisticação, durabilidade, cores neutras e linhas sóbrias, são características do design escandinavo.

Ainda com base no mesmo autor, o design escandinavo passou a se tornar notório na década de 1950, devido à sua funcionalidade e praticidade, mas a sua história começa muito antes, na primeira metade do século XIX, com o término do sistema tradicional de produção artesanal devido à evolução da produção industrial. Enquanto muitos países viam suas tradições artesanais serem perdidas, a Suécia criou em 1845 a Sociedade Sueca de Artesanato e Design Industrial que visava a evolução dos meios de produção, porém sem perder as características que tornavam o produto artesanal escandinavo digno de excelência.

Essa tentativa de manutenção da excelência artesanal ocorreu não só na Suécia, como também nos demais países escandinavos, que passaram a trabalhar em busca da modernização que tornasse seus produtos competitivos e atraentes internacionalmente, mas sempre sem perder a qualidade que os caracterizava (PORTO DESIGN, 2014). Assim, as características do design escandinavo concordam com o conceito do material que é direto, claro, de fácil compreensão e funcional.

\subsection{Etapa 2 - Design (Projetar)}

Depois de uma análise bem fundamentada, definição dos requisitos do material didático e a elaboração do conceito, iniciou-se a etapa criativa de fato, a geração de alternativas. Com isso, foram realizadas propostas representadas por esboços e desenhos. Analisando as gerações e comparando com o tema escolhido, ficou definido que o layout da capa, das páginas e o formato do material didático seguiria a linguagem das alternativas escolhidas da Figura 6. Algumas alterações foram feitas ao final, porém essas alternativas formataram a base para o projeto.

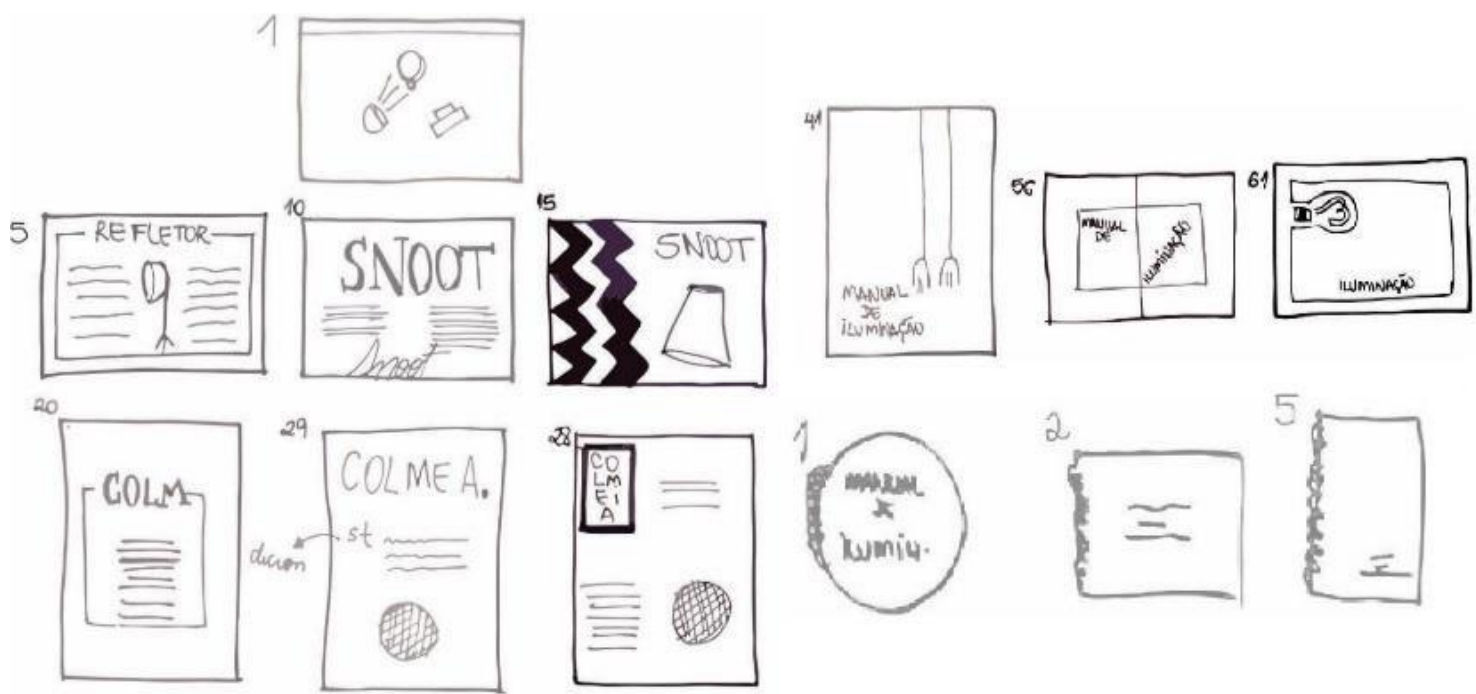

Figura 6 - Geração de alternativas escolhidas.

Fonte: Rodrigues (2017).

Analisando as alternativas, foram tomadas algumas decisões: o material didático seria em formato digital, porém, se ele for impresso, seria recomendado a orientação horizontal em tamanho A5. As ilustrações seriam com traços finos; o material seria de navegação fácil, direto, agradável e intuitivo; o layout deveria transmitir confiança, seriedade e ajudar na economia do tempo do usuário.

\subsection{Etapa 3 - Develop (Desenvolver)}

O material foi desenvolvido com base nas alternativas escolhidas e na pesquisa feita com os alunos na etapa de análise. Antes de começar a criar, foi feito grids modulares e em colunas para guiar a diagramação das páginas (Figura 7). 

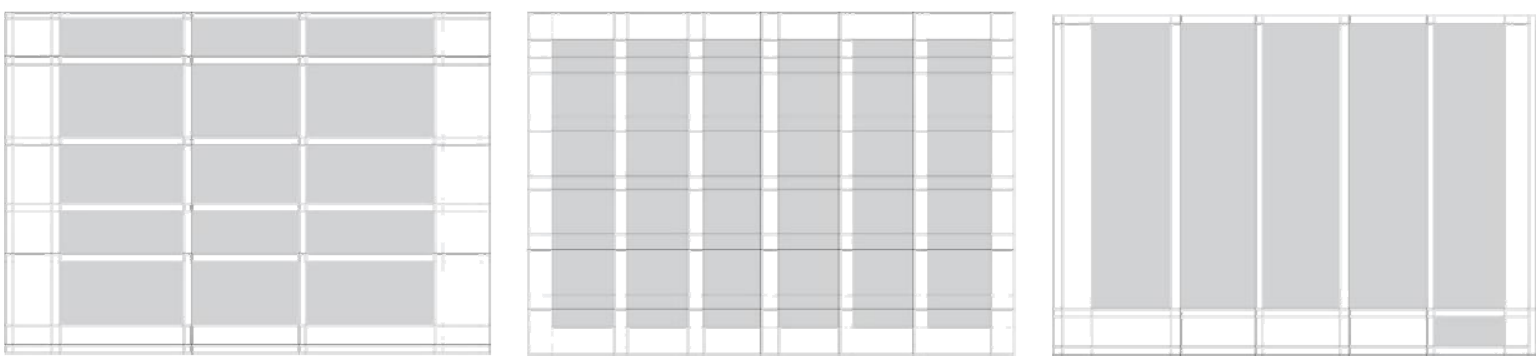

Figura 7 - Grids modulares e em coluna.

Fonte: Rodrigues (2017).

Em seguida, foram criados quatro layouts diferentes para compor o material: um para as explicações do que era luz dura, luz suave, luz frontal, luz lateral, high key, low key e contraluz (Figura 8); e os outros três eram para diferenciar cada equipamento fotográfico e suas explanações de como realizar cada técnica (Figura 9). As fontes escolhidas para compor o material foram a Vanitas e a Handycheera.

A capa foi elaborada com a cor preta e com o bege para representar a dualidade luz e sombra, o que remete ao assunto principal do material. Há também uma transparência branca na frente das cores para deixar o título o mais legível possível. Seria muito simplista colocar como título "Manual de iluminação artificial na fotografia", então, foi definido colocar um nome que remetesse ao conteúdo, mas que fosse minimalista (adequado ao tema escandinavo), ou seja, com a menor quantidade de informação (palavras) possível e que chamasse mais atenção, por isso foi intitulado "Manual de como iluminar". Em seguida, o sumário e a introdução, que são compostos por layouts simples, branco, sem outras informações além do texto.

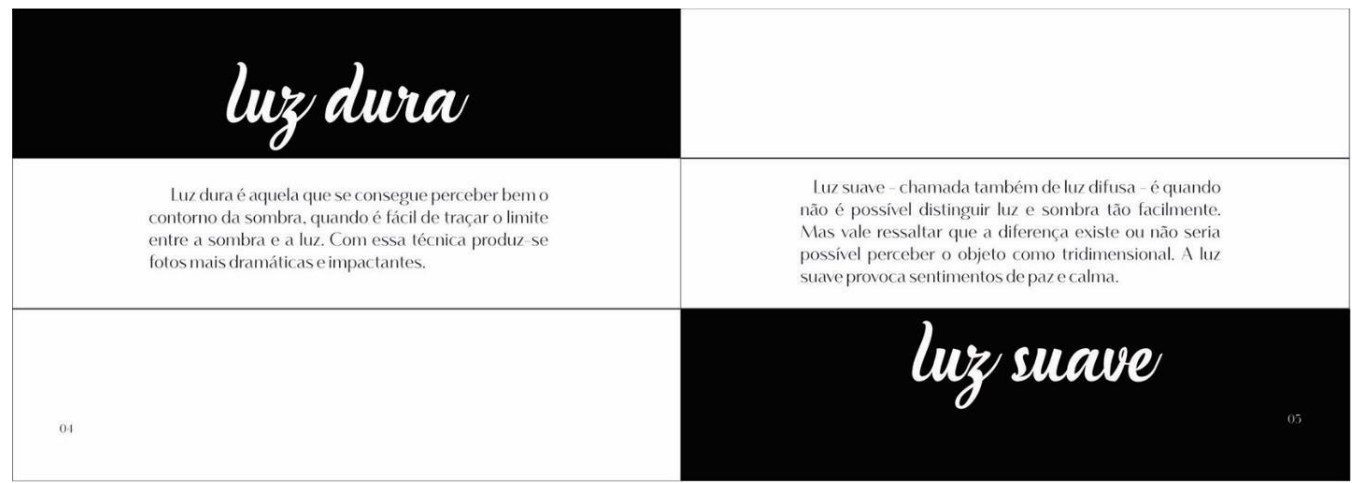

Figura 8 - Layout para as páginas de explicação das técnicas de iluminação fotográfica. Fonte: Rodrigues (2017).
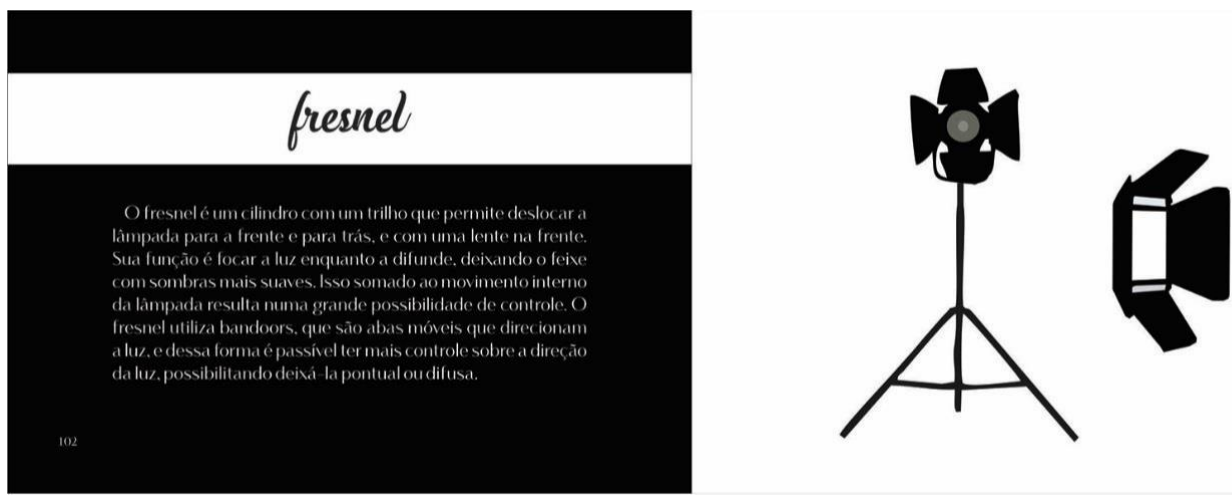

Figura 9 - Um dos layouts das páginas de apresentação dos equipamentos (layout preto). Fonte: Rodrigues (2017).

Como o objetivo desse material didático é apresentar uma breve descrição dos equipamentos de iluminação artificial que se encontram no laboratório de Narrativas Visuais da UTFPR e explicar como eles são utilizados para compor as técnicas de iluminação na fotografia, com textos 
informativos, claros e sintéticos, para não causar desconforto ao leitor, foi verificada a necessidade da combinação de texto e imagem para o conteúdo ser melhor fixado, pois as imagens reforçam o conteúdo do texto. Segundo Haslan (2007), o equilíbrio entre texto e imagem pode garantir o interesse por parte do leitor. Por isso, além de fazer a descrição do equipamento no material didático, foi colocada uma imagem vetorizada dele para o aluno poder reconhece-lo com facilidade. Na parte sobre como utilizá-lo também foram colocadas imagens para exemplificar. Vale ressaltar que não foram utilizadas fotografias no material didático, apenas ilustrações e vetores, diretamente ligados ao Design.

O material em arquivo digital foi feito em formato "rolagem infinita", para que o usuário não precisasse clicar em nada para passar as páginas, sendo apenas necessário deslizar a tela para visualizá-las. Já no arquivo impresso, a capa e a contracapa do material foram impressas em papel couchê $300 \mathrm{~g}$ e o miolo em papel color plus $120 \mathrm{~g}$. Além disso, foi feito uma capa em papel laser film para ser colocado na frente da capa principal. A encadernação foi do tipo wire-o para dar melhor sustentação.

\subsection{Etapa 4 - Implement (Implementar)}

Depois do material pronto, ele foi disponibilizado na versão impressa e em PDF em uma aula de Fotografia da UTFPR para que os alunos o utilizassem e o testassem. Nesta semana (da avaliação), a professora da disciplina de Fotografia estava abordando em suas aulas o conteúdo sobre iluminação com luz dura e luz suave, então os alunos leram o material - como mostra a Figura 10 - e aplicaram as técnicas com base na explicação oral do professor e nas informações contidas no material didático (Figura 11).
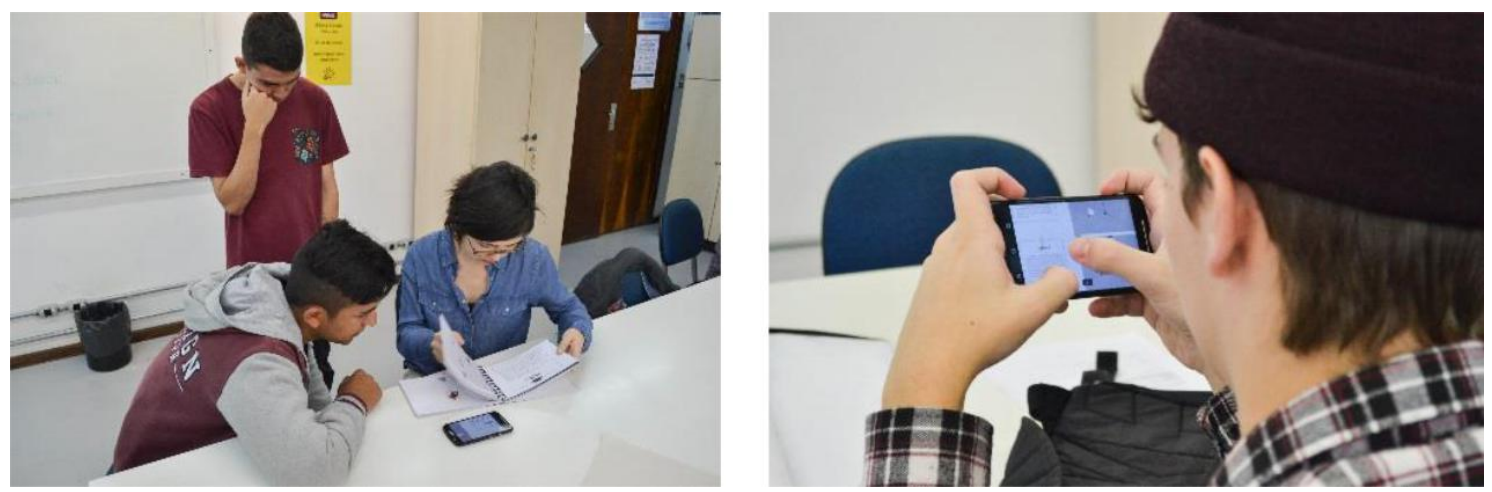

Figura 10 - Alunos lendo o material didático. Fonte: Rodrigues (2017).
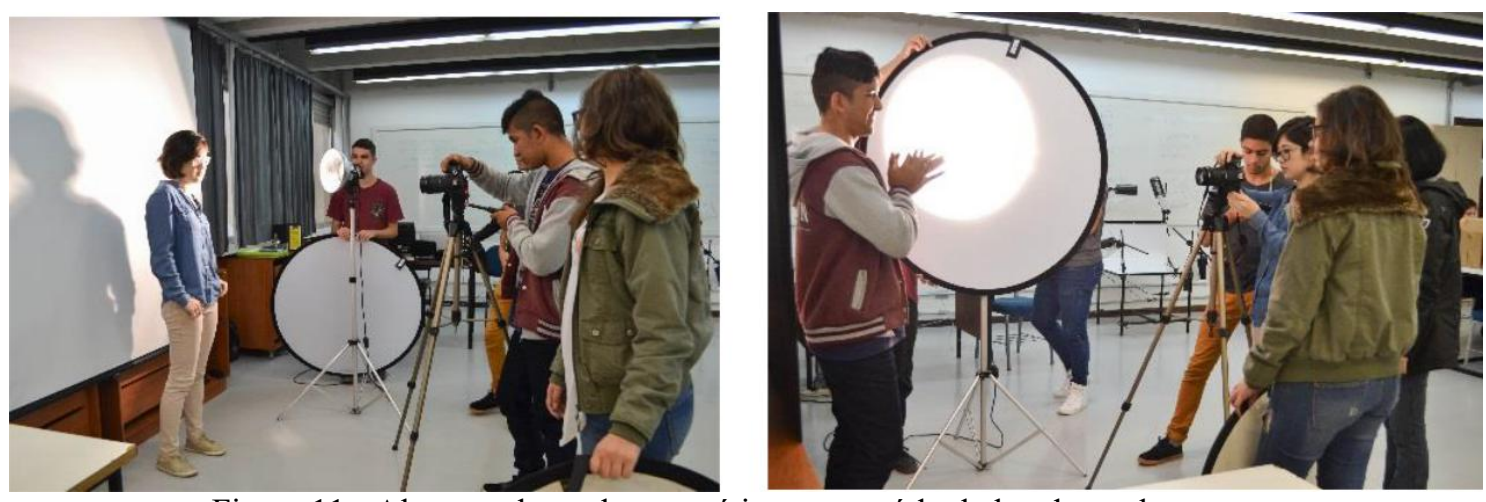

Figura 11 - Alunos colocando em prática o conteúdo de luz dura e luz suave. Fonte: Rodrigues (2017).

Alguns alunos cederam as fotos tiradas nesta aula para que se pudesse compartilhar o resultado do aprendizado com o material didático. Na Figura 12, foi trabalhado a técnica de luz dura com um refletor. Pela sombra, pode-se concluir que o refletor estava na lateral do lado direito. A luz dura faz com que as sombras fiquem bem marcadas, e isso é possível perceber na sombra dos modelos 
na parede e a sombra que desenha o rosto, deixando bem escuro um lado e o outro bem claro, até estourando a foto em alguns pontos.

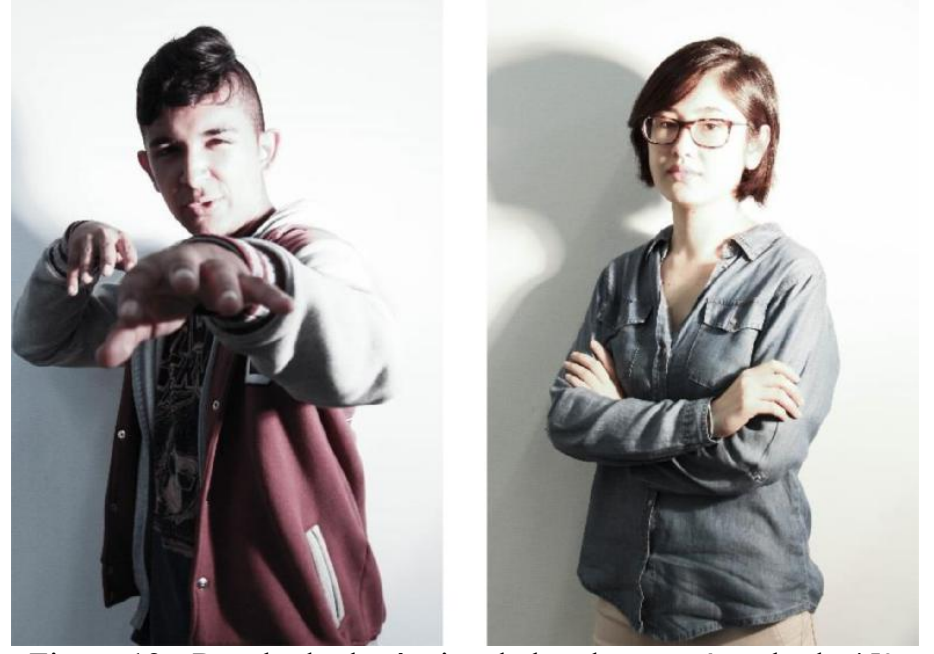

Figura 12 - Resultado da técnica de luz dura em ângulo de $45^{\circ}$.

Fonte: Rodrigues (2017). Modelos Fabyson Leonardy Novais e Ângela Mayume Oyafuso.

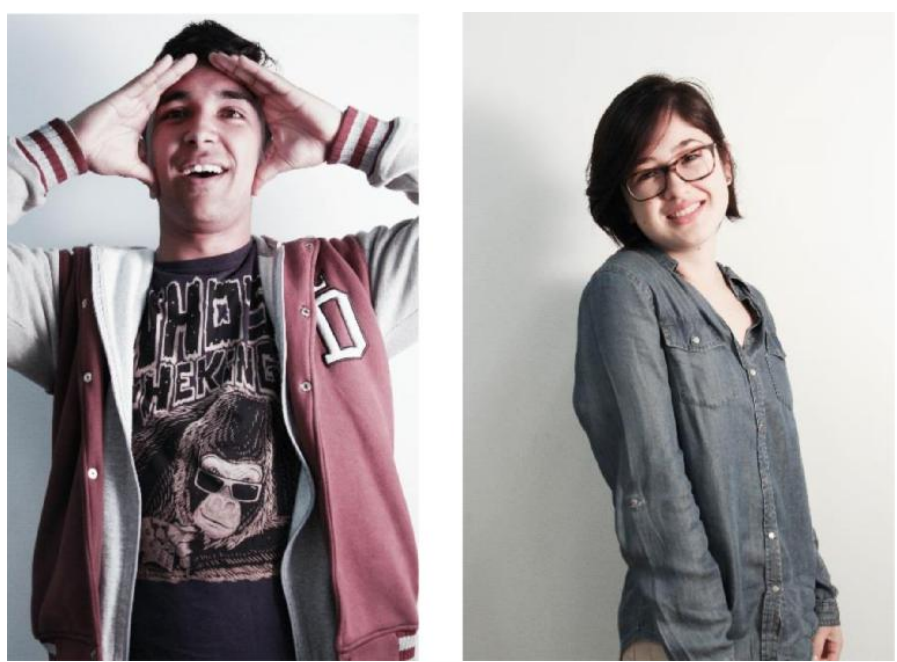

Figura 13 - Resultado da técnica de luz suave em ângulo de $45^{\circ}$.

Fonte: Rodrigues (2017). Modelos Fabyson Leonardy Novais e Ângela Mayume Oyafuso.

Já a figura 13 trata da luz suave. Esta técnica é o contrário da luz dura, ou seja, ela cria imagens com sombras mais "moderadas", apesar de existir sombras - e isso é bom, pois as sombras dão volume e textura a imagem - elas não apresentam contornos tão definidos. Depois desta análise das fotos, é possível concluir que o material foi útil para o aprendizado. É importante lembrar também que houve a preocupação com o direito de imagem, por isso, os alunos das imagens acima assinaram um termo autorizando o uso de imagem no presente trabalho final.

\subsection{Etapa 5 - Evaluate (Avaliar)}

Após a implementação, os alunos responderam um questionário avaliando o material apresentado. No geral, o feedback foi positivo, porém alguns deram sugestões de mudanças em relação ao layout. No total, 17 pessoas responderam o questionário de avaliação do material. A faixa etária dos respondentes ficou entre 18 e 32 anos, sendo que 9 eram do sexo feminino e 8 do sexo masculino. Das 17, 14 pessoas eram do curso de Tecnologia em Design Gráfico e apenas 3 pessoas do Bacharelado em Design.

Em relação a clareza e compreensão na definição dos equipamentos e as técnicas de iluminação, $82 \%$ das pessoas disseram que atendia as expectativas ou que estava além das 
expectativas esperadas. $35 \%$ dos alunos responderam que o entendimento do passo a passo de como utilizar os equipamentos estava de acordo com as expectativas. Em relação a facilidade de visualização dos ícones de cada passo, 53\% disseram estar acima das expectativas. E por fim, sobre a facilidade de visualizar e compreender o resultado que o equipamento pode oferecer, houve um empate, $35 \%$ pessoas responderam estar acima das expectativas e 35\% disseram atender as expectativas. Além disso, todos os alunos responderam que o material é um ótimo apoio complementar em sala de aula.

Ademais, os alunos deram sugestões de como o material poderia ser melhorado, mas antes de fazer qualquer alteração, foi realizado um encontro com a orientadora do trabalho em questão para coletar suas sugestões sobre o material e as possíveis mudanças. Em paralelo, também foi feito uma reunião com uma professora Designer Gráfica do departamento para recolher sua opinião sobre os layouts, fontes, diagramação, impressão e encadernação. Todas as recomendações foram levadas em consideração para fazer a versão final do projeto.

\subsection{Ajustes e apresentação do produto final}

Com as sugestões efetuadas pelos alunos e os profissionais da área, a autora do presente trabalho aplicou as devidas alterações, começando pela diagramação. Foi revisto o conceito dos grids e para a versão final foi utilizado a proporção áurea (Figura 14) para o layout das páginas. Essa regra de diagramação é um suporte que ajuda na construção de composições visuais de proporções perfeitas.

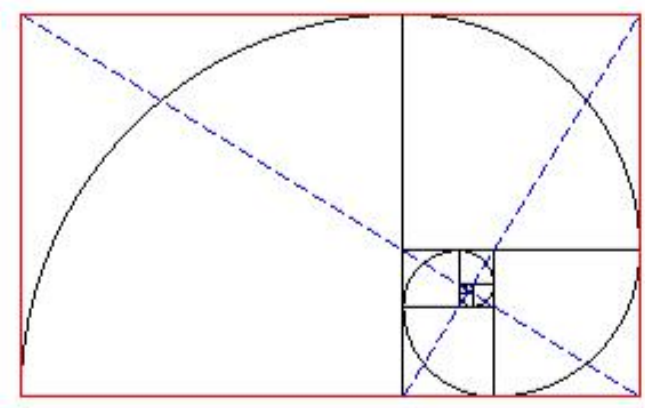

Figura 14 - Retângulos e espiral áurea. Fonte: Nadys (2017).

Além disso, com a utilização dessa proporção foi possível diagramar páginas mais "harmoniosas", que mostram unidade entre si, exemplo disso, pode-se ver nas páginas em que se explica sobre técnicas de iluminação fotográfica, se postas juntas, uma do lado da outra, percebe-se o alinhamento entre o texto, dando sensação de algo contínuo (Figura 15).

No "boneco" foram feitos quatro layouts diferentes e na versão final são apenas três: um para o sumário (Figura 15), outro para a apresentação dos equipamentos de iluminação (Figura 17), e o último para falar das técnicas de iluminação fotográfica (Figura 16). Ademais, a fonte foi diminuída de 19 pontos para 12, para que pudesse ser introduzido mais conteúdos e assim ficasse mais completo. A fonte também mudou, o que era Handycheera passou a ser Trajano Pro 3 e o que era Vanitas foi trocado por MetroLite LT Two. A decisão de mudança foi para passar maior impressão de formalidade do material e pelo fato de as fontes anteriores ficarem ilegíveis em algumas situações. 

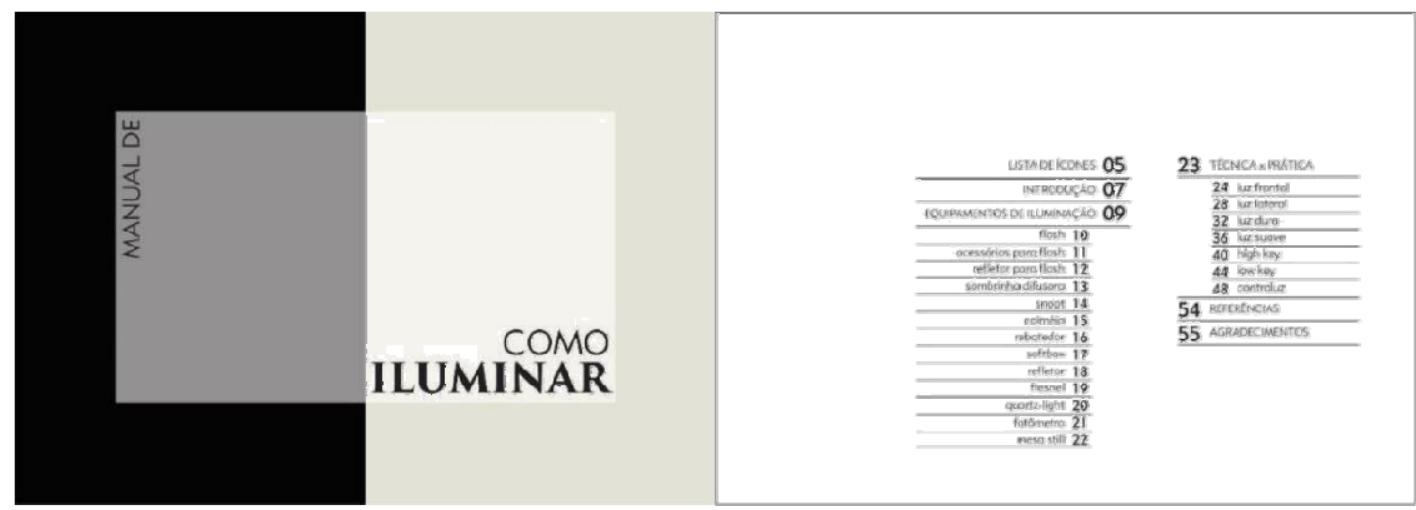

Figura 15 - Versão final do layout da capa e do sumário do material didático. Fonte: Rodrigues (2017).

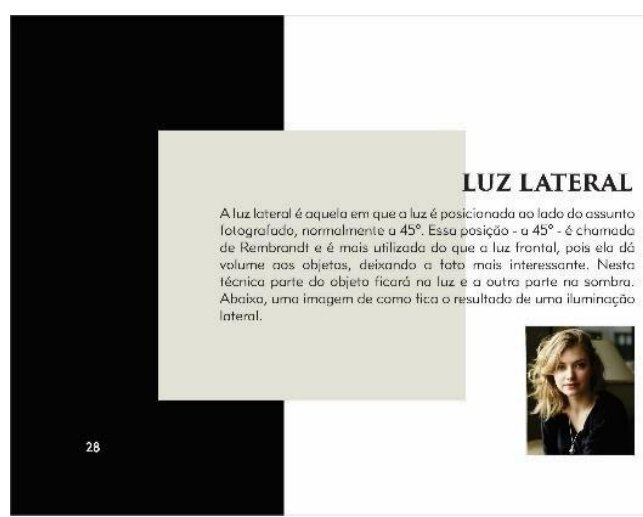

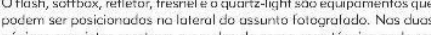
páginas seguintes mastram exemplos de como essa técrica pode ser
leita, no local onde está posicionado o flash e o refleler é possivel Iroccor por qualquer equiparnento citado acimo.

Figura 16 - Versão final do layout das páginas que explicam sobre iluminação fotográfica. Fonte: Rodrigues (2017).
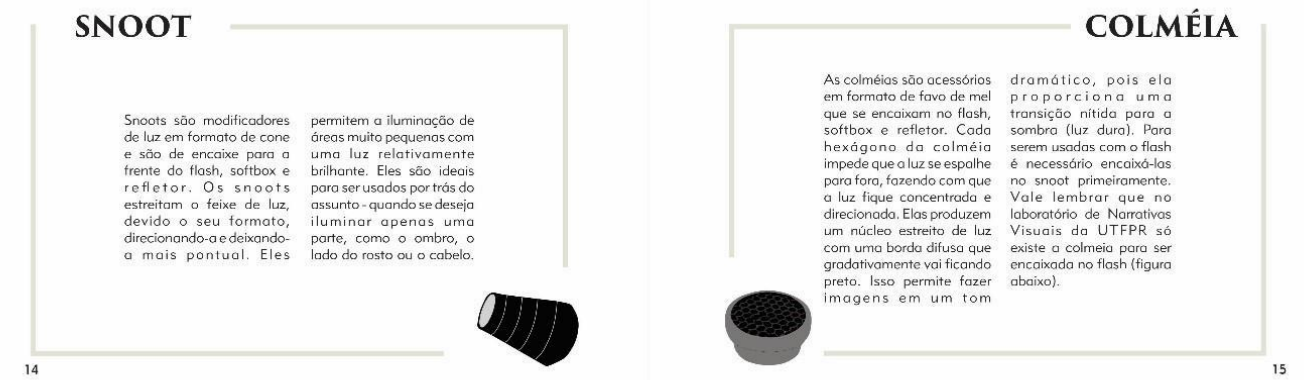

Figura 17 - Versão final do layout das páginas apresentam os materiais de iluminação. Fonte: Rodrigues (2017).
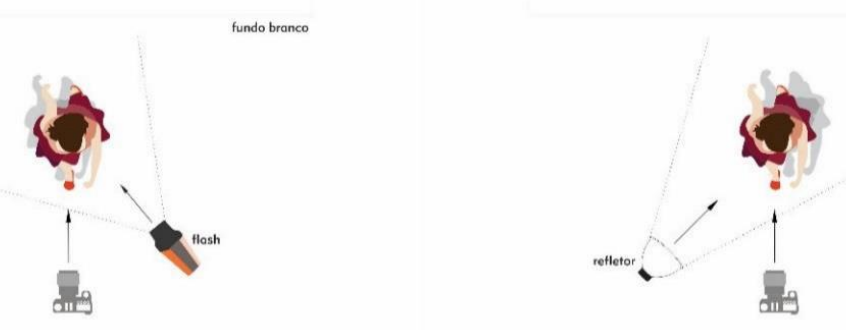

Figura 18 - Versão final do layout das páginas ilustrativas.

Fonte: Rodrigues (2017). 
Os layouts das páginas da introdução, dos agradecimentos, das referências, capa e contracapa permaneceram como estava no "boneco". Algo que também se manteve foram as ilustrações e a forma como são dispostas para exemplificar as técnicas de iluminação (Figura 18), pois os alunos deram um feedback bastante positivo em relação a esses elementos. Nas páginas que explicam as técnicas de iluminação fotográfica também foi colocado uma fotografia para exemplificar como deverá ser o resultado da imagem ao reproduzir determinada técnica (Figura 16).

A ordem do material foi modificada também. No material didático atual a ordem é: capa, sumário, lista de ícones, introdução, apresentação dos equipamentos de iluminação, técnicas de iluminação com a descrição dos equipamentos que podem ser utilizados para realiza-las, referências, agradecimentos e contracapa. Dessa maneira, foi possível compactar o material didático, que de 136 páginas passou para 54 páginas. Além disso, esta disposição ficou mais viável para o entendimento da teoria abordada no material, tornando-o mais simplificado e organizado. A paleta de cores também sofreu alterações. Foi percebido que o degrade de marrons acabava por cansar a leitura, por isso, essa troca. A paleta atual dá a impressão de algo clean e confiável, com menos cores e com maior conexão com o tema do escandinavo (Figura 19).

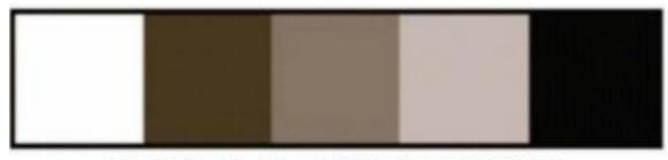

PALETAANTERIOR

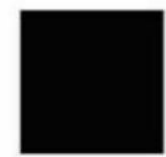

PALETAATUAL

Figura 19 - Paleta de cores anterior e atual. Fonte: Rodrigues (2017).

Outra alteração foi em relação a capa e a contracapa. No "boneco", elas foram impressas em papel couchê $300 \mathrm{mg}$, porém considerou-se necessária a utilização da capa dura para que o material tivesse mais durabilidade, já que o material fica disponível no laboratório e é manuseado por vários alunos, o que causa bastante desgaste. A capa e a contracapa do "boneco" podem ser facilmente rasgadas e destacadas, por isso a escolha da capa dura, ela proporciona resistência ao material, além de conservar melhor as páginas internas. O miolo, no "boneco" foi feito em color plus $120 \mathrm{~g} / \mathrm{m}^{2}$, mas na versão final ele foi impresso em couchê fosco $170 \mathrm{~g} / \mathrm{m}^{2}$ que proporciona maior segurança no manuseio por ser mais espesso e o couchê, apesar de ser fosco, tem um leve brilho (este pequeno brilho não interfere na leitura), o que torna o material mais apresentável e "profissional". No entanto o tipo de encadernação wire-o foi mantido.

O sistema de "rolagem infinita" para navegar no material didático no modo digital foi preservado, além de ser a melhor forma de manusear o material digital, não houve nenhuma sugestão por parte do usuário final.

\section{Considerações finais}

O material didático ocupa um lugar significativo na prática docente, no aprendizado dos alunos e na melhoria do ensino em geral. Por isso, é de extrema importância que os materiais disponíveis sejam eficazes e atrativos. O projeto foi desenvolvido com base nesse reconhecimento da influência do ensino, para isso, foram necessários o estudo sobre fotografia básica, equipamento de iluminação (e suas respectivas funções) e análises dos materiais didáticos existentes atualmente. $\mathrm{O}$ material desenvolvido poderá ser uma ferramenta para unificar o ensino e dinamizá-lo. É um material eficaz e confiável, diferente de tudo que já existe, prático, direto e de simples compreensão. Com o auxílio de profissionais do setor foi esclarecido os pontos fundamentais para o caminho até o objetivo proposto, além de direcionarem para a construção do conceito criado.

A metodologia utilizada no processo para a criação do material didático, bem como as diversas referências usadas, explanam e ilustraram os pontos essenciais para o percurso até o objetivo fixado. Após a conclusão do presente trabalho, foi possível ponderar sobre os caminhos percorridos para atingir os resultados conquistados. Acredita-se que o objetivo foi atingido. De fato, o material foi criado e aprovado pelos alunos, servindo de apoio para a prática em sala de aula. 


\section{Digital Didatic Material for the Teaching of Artificial Lighting in Photography}

Abstract: This work aims to describe the process of developing a digital didactic material for the Visual Narratives Laboratory of the Academic Department of Industrial Design of the Federal Technological University of Paraná (UTFPR). The design project had the purpose of improving and unifying the teaching and learning in the photographic area, addressing the subject of artificial lighting. The ADDIE methodology was used to guide the analyzes and points to be observed and recorded in the present material. The project was divided into five stages: analysis, generation of alternatives, development, implementation and evaluation. First, the identification of all lighting equipment available in the laboratory was performed through the capture of images. Next, each material was conceptualized with its respective technical specifications and described for which purposes can be used. In addition, an in-depth study of lighting techniques in photography and the camera's functions influencing illumination were required during this phase of analysis. This theoretical foundation was important so that the material was composed of appropriate contents. In addition, observations and records were made during the photography classes so that it was possible to understand the difficulties and the needs on the part of the students and, thus, to develop a more efficient and attractive material. From the observations made in the analysis phase, it was possible to arrive at the concept of the project: to create a digital didactic material in the style of the Scandinavian design following diagramming rules to compose the layouts. The Scandinavian design has features like minimalism, straight shapes, neutral colors, simplicity and elegance. With this defined, the creative phase began, with the generation of alternatives, which occurred through handmade drawings. Next, the most viable alternatives were chosen, that is, those that could provide greater receptivity on the part of the user. With this information, it was possible to move to the practical part, the execution of the project itself. For the realization of the project, were used softwares like CorelDraw, Illustrator and Photoshop. After completion, the implementation and then evaluation of the material by students and teachers occurred. Finally, the suggested changes were made, such as the change in the diagramming rule (modular and column grids were replaced by the golden proportion rule), the font size that composed the text (from 19 points to 12), inclusion Of more information, the way of presentation of the material (final version with hard cover), among other modifications. The content of the teaching materials created included a brief explanation of photo lighting techniques such as: front, side, hard, soft, high key, low key and backlight, description of each photographic equipment and lighting accessories available in the Laboratory, and how these can be used to compose lighting techniques. At first, the material was prepared for the digital medium for ease of access, however, a version was printed and is available in the lab for quick reference. In short, the result of this project was a very practical, straightforward, easy-to-understand teaching material with the simplicity and elegance of Scandinavian design.

Keywords: Scandinavian design; ADDIE Methodology; Studio photography; Photographic equipment

\section{Referências bibliográficas}

DALBELLO, Erica. Photopro: o que é high key na fotografia?. Disponível em <http://www.photopro.com.br/tutoriais-gratis/high-key-fotografia/>. Acesso em: 05 dez. 2016.

FILATRO, Andrea. Design Instrucional contextualizado: educação e tecnologia. São Paulo: Senac. 2004.

GURAN, Milton. Linguagem fotográfica e informação. Rio Fundo Editora. Rio de Janeiro: 1992.

HASLAM, Andrew. O livro e o Designer II. São Paulo: Rosari, 2007.

LIMA, Willian. Fotografia high key e low key: o que são e como fazer. Disponível em

<http://falandodefoto.com.br/fotografias-high-key-e-low-key/>. Acesso em: 15 dez. 2016. 
LÖBACH, Bernard. Design Industrial: bases para a configuração dos produtos industriais. Editora Edgar Blucher. São Paulo: 2001, p. 153.

LOURENÇO, Gil. Fotografia de contraluz. Disponível em < http://glourenco.com/>. Acesso em: 28 nov. 2016.

LÜERSEN, Angélica. Fotografia: A escrita da luz. VIII Intercom Sul: Passo Fundo (RS), 2007.

NADYS, Chrishia. La esperial de proporción aurea y la luz de metatrón. Disponível em $<$ http://conexionestelar.webnode.es/news/la-espiral-de-proporcion-aurea-y-la-luz-demetatron/>. Acesso em: 14 mai 2017.

PORTO DESIGN. Design escandinavo: ícone de vanguarda e bom gosto. Publicado em 09 set. 2014.

Disponível em: <http://www.portodesign.com.br/blog/design-escandinavo-icone-da-vanguarda-ebom-gosto/>. Acesso em: 05 mar. 2017.

RAMALHO, José. Fotografia digital. Rio de Janeiro: Elsevier Editora Ltda, 2004.

REGINA, Claudia. Dicas de fotografia. Disponível em <http://www.dicasdefotografia.com.br>.

Acesso em: 05 dez. 2016.

REGINA, Claudia; TAKAZAKI, Silmara. Dicas de fotografia. Rio de Janeiro: 2015.

RODRIGUES, Beatriz. Material didático digital para o ensino de iluminação artificial na

fotografia. 2017. 135 f. Trabalho de Conclusão de Curso - Bacharelado em Design, Universidade Tecnológica Federal do Paraná. Curitiba, 2017.

ROWSE, Darren. Introduction to White Balance. Disponível em <https://digital-photographyschool.com/introduction-to-white-balance/> . Acesso em: 11 mai 2017.

SALGADO, Maria Umbelina Caiafa. Características de um bom material impresso para a educação a distância. Ministério da Educação, Seed. Brasília: 2005, p. 154-159.

VIEIRA, Isis; CORREA, Rômulo. Cor e luz. XX Expocom: Niterói (RJ), 2013.

WORTH, R. Fotografia de contraluz. Disponível em:

<http://www.nma.gov.au/online_features/digital_landmarks_2012/photo_media_student_work/rebe cc a_worth>. Acesso em: 29 nov. 2016. 